\title{
COVID-19 Vaccine Uptake, Unmet Need and Reported Side Effect in Nigeria: an Online Cross-sectional Study
}

Olanrewaju Davies Eniade ( $\sim$ eniadetreasure@gmail.com )

Institute of Human Virology https://orcid.org/0000-0001-7142-3818

Omowumi Okedare

University of Ibadan, Ibadan, Oyo State

Abayomi T. Olarinmoye

Adeleke University, Ede

Yusuff Olasunkanmi

University of Ibadan, Ibadan, Oyo State

Agofure Otovwe

Novena University, Delta State, Nigeria

Funke Akintunde5

Adeleke University, Ede, Osun State

Adebukola Aniyeloye

Adeleke University, Ede, Osun State

Research Article

Keywords: herd immunity, unmet need, COVID-19, vaccine, side effects

Posted Date: February 7th, 2022

DOI: https://doi.org/10.21203/rs.3.rs-1332716/v1

License: (c) (i) This work is licensed under a Creative Commons Attribution 4.0 International License. Read Full License

Version of Record: A version of this preprint was published at Asian Journal of Research in Infectious Diseases on April 11th, 2022. See the published version at https://doi.org/10.9734/ajrid/2022/v9i430274. 


\section{Abstract}

The COVID-19 pandemic continues to wreak havoc in Nigeria, with more cases and deaths reported every day. However, vaccine development and uptake are believed to aid the fight against this outbreak. We investigated vaccine uptake, unmet need for vaccine, and reported side effects among the populace. An online cross-sectional study was conducted among 417 adults from the six geopolitical zones in Nigeria using the online data collection tool, Kobo-toolbox. We obtained information on socio-demographic characteristics, vaccine uptake, unmet need, and related side effects of COVID-19 vaccine. Descriptive analysis, binary logistic regression were done using Stata MP 16

The mean age of the respondents was $32.1 \pm 10.7$ years. About half (49.9\%) were aged below 30 years of age. The majority were females (63.1\%), Christians (89.2\%), and urban dwellers (74.6\%). Majority (89.2\%) of respondents know that vaccines are beneficial to health, and $41.2 \%$ have received the COVD-19 vaccine. Unmet need for COVID-19 vaccine was $74.3 \%$ and herd immunity was estimated as $93.1 \%$. Respondents working in the private sector (AOR=0.32, $95 \%$ $\mathrm{Cl}=0.11-0.90$ ), and who said COVID-19 vaccine is not beneficial to health ( $\mathrm{AOR}=0.04,95 \% \mathrm{Cl}=0.01-0.29$ ) were less likely to receive COVID-19 vaccine, while those who have tested for COVID-19 (AOR=3.93, 95\%Cl=1.98-7.84) have a higher likelihood of receiving COVID-19 vaccine.

Continuous awareness for COVID-19 vaccine is needed. Government needs to persistently assure citizens of the safety and efficacy of the vaccines. Also, this study recommends that the administration of a highly effective vaccine would result in achievable herd immunity and curb the transmission of COVID-19 virus.

\section{Introduction}

Since the COVID-19 pandemic started in January 2020, there has been an increase in mortality and morbidity worldwide. As of August 8, 2021, there have been more than 202 million cases of COVID-19 worldwide and over 4 million mortality (COVID-19 Repository, 2021). The trial for COVID-19 vaccine started as soon as COVID-19 was announced a pandemic. At the beginning of the pandemic, non-pharmaceutical interventions such as the use of face masks, hand washing, use of hand sanitizer, social distancing, and isolation were the recommended preventive measures. However, as the pandemic progressed there was a need for large-scale pharmaceutical intervention to achieve herd immunity.

Vaccines are biological products administered to healthy individuals that confer immunity against infection and disease. They could be inactivated organisms or live-attenuated viruses. Vaccines work in a way that prepares the immune system to respond to natural infection in the future. They are recommended for all humans and require safety and monitoring for potential side effects (Piot et al., 2019). The benefits of vaccination are numerous and not to only those vaccinated, but to other members of their families and community. Adequate coverage of individuals vaccinated confers a "herd immunity" which reduces or terminates the continuous transmission of the disease within the population. Vaccination has socio-economic, physical development, educational, social, and health advantages (Piot et al., 2019). Several brands of COVID-19 vaccines are available, they include; Johnson \& Johnson, Oxford/AstraZeneca, Pfizer/BioNTech, Sinovac, Sputnik V, Sinopharn/Beijing, Moderna, Covaxin, Abdala, Soberana02, CanSino, EpiVacCorona (Ritchie et al., 2020).

One key step in stopping the COVID-19 pandemic is to ensure that a large proportion of the world population is vaccinated. Vaccines have proved effective and efficient in reducing mortality due to infectious disease globally (Piot et al., 2019; Ritchie et al., 2020). Governments all over the world have been urged to ensure large-scale, equitable access and distribution of COVID-19 vaccines (Lazarus et al., 2020). As of August 8, 2021, less than one-third of the world population has received at least a dose of any type of COVID-19 vaccine, with $15.4 \%$ receiving the complete dose. Globally, an estimated 4.43 billion doses of COVID-19 vaccines have been administered. However, the population of people in low-income countries that have been vaccinated is only one-tenth (Ritchie et al., 2020; WHO Africa, 2021). COVID-19 vaccination rate in Nigeria stands at 1.91 per 100, one of the lowest globally (Ritchie et al., 2020). Vaccine hesitancy and misinformation impede uptake and achieving the herd immunity desired in the case of COVID-19 (Lazarus et al., 2020).

Vaccine hesitancy, a major impediment to vaccine uptake has been documented globally, but especially in Africa. A major concern towards the COVID-19 vaccine was the accelerated pace of the development of the vaccine, mistrust of the government's response, and safety (Eniade et al., 2021; Lazarus et al., 2020; Piot et al., 2019; Schaffer Deroo et al., 2020; Wang et al., 2020). It was reported by WHO that several African countries have paused COVID-19 vaccine rollouts because of safety concerns, due to fears of side effects reported in developed countries (WHO Africa, 2021). Social media contributed greatly to the spread of myths and misconceptions on COVID-19 vaccines, as well as the safety and efficacy of the vaccine. Unfortunately, many African countries cannot track and provide up-to-date information on the side effects of the COVID-19 vaccine and share empirical information on the benefits (WHO Africa, 2021) to assure and demystify the widespread misconceptions.

To achieve herd immunity for COVID-19, about $55 \%$ to $82 \%$ of the population must be vaccinated, depending on the genetic, environmental, and socio-cultural factors of the people (Sanche et al., 2020). Despite the obvious benefits of vaccines and vaccination, there is still widespread delay or refusal to get vaccinated (OECD, 2021; Piot et al., 2019).

In our previous study, we documented the willingness of Nigerians to receive the COVID-19 vaccines when it is made available, which shows that less than half of the population surveyed were willing to take the vaccine (Eniade et al., 2021). This brings concern and the need to further investigate the uptake of the vaccine, now that they are available. Also, an unmet need for the vaccine and reported side effects.

\section{Materials And Methods}

This was a cross-sectional study carried out in Nigeria; the most populous nation in Africa with an estimated population of about 200 million. Nigeria has 36 States divided into six geopolitical zones (South-west, South-east, South-south, North-west, North-east, and North-central). The study participants were adults aged 18 years and above who consented to participate in the study. We did not perform a formal sample size calculation and included all participants who 
responded to the questionnaire within the time frame of the study, August to October 2021. The study was an online survey, and information was obtained using a well-structured questionnaire designed using the Kobo toolbox application, an online data collection tool. The questionnaire was adapted from several published literature and comprised of two sections A and B namely, socio-demographic characteristics of respondents and the uptake, unmet and related side effects on COVID-19 vaccine. The link generated for the questionnaire was sent to various social media platforms, and privately to individuals. The questionnaire took respondents about three minutes to complete.

The outcome variable in this study was COVID-19 vaccine uptake (Yes/No). Respondents were said to have an unmet need for the vaccine if he/she was willing to take the vaccine but had no access to take the vaccine. The independent variables were the socio-demographic characteristics of the respondents (Age, Gender, Level of education, Religion, Marital status, Type of residence, and Occupation), Knowledge of Vaccines, Exposure to COVID-19 virus, Access to COVID-19 vaccine.

The herd immunity estimation.

R0 is the estimated/expected number of infected individuals when an infected person enters a population that is immunologically naïve to the infectious agent. Effective reproduction number $(\mathrm{R})$ is the expected/estimated number of infected individuals when an infected (and infectious) individual enters a population that is not immunologically naive to the infectious agent in question and the population is indeed a mix of immunologically naive and immunologically experienced individuals.

Formula:

$$
\text { Herd immunity }=\frac{1-\frac{1}{R_{0}}}{V}
$$

Where $\mathrm{R}_{0}$ ranges between 0.18 and 2.3 according to the estimate reported in a study conducted in Nigeria (Adekunle et al., 2020). And $\mathrm{V}$ is the vaccine efficacy The dataset was exported from the Kobo toolbox to an excel sheet and then exported into Stata Version 16 for analysis. Descriptive statistics (frequencies, percentages and charts) were presented for the outcome variable and explanatory variables. The herd immunity in Nigeria was calculated using the existing formula and estimated reproductive number $R_{0}$. The assessment of factors associated with COVID-19 vaccine uptake was carried out using binary logistic regression analysis, after which factors that were significant at the crude level were adjusted to control for confounding variables.

\section{Results}

\section{Socio-demographic characteristics of the respondents}

The socio-demographic characteristics of respondents are presented in table 1. The mean age of the respondents was $32.1 \pm 10.7$ years. About half (49.9\%) were aged below 30 years, and $6.2 \%$ were aged above 49 years. Majority of the respondents were females $(63.1 \%)$, had tertiary education ( $97.8 \%)$, and were Christians (89.2\%). About $46 \%$ were currently married, and $0.7 \%$ was widow/widower. There were more urban dwellers (74.6\%) than peri-urban (14.6\%), and rural dwellers (10.8\%). The distribution of the respondents' occupations was: Health worker (18.0\%), Civil servants (19.7\%), private sector (12.0\%), unemployed (7.7\%), self-employed (15.1\%), and students (27.6\%). Median family size was $5(4,6)$, and median income was \#71,000 (\#31,500, 125,000).

\section{Table 1: Socio-demographic Characteristics of the respondents}




\begin{tabular}{|c|c|c|}
\hline Variables & Frequency $(n=417)$ & Percentage (\%) \\
\hline Age mean(SD) & $32.1(10.7)$ & \\
\hline \multicolumn{3}{|l|}{ Age group (years) } \\
\hline$<30$ & 208 & 49.9 \\
\hline $30-39$ & 111 & 26.6 \\
\hline $40-49$ & 72 & 17.3 \\
\hline$>49$ & 26 & 6.2 \\
\hline \multicolumn{3}{|l|}{ Gender } \\
\hline Female & 263 & 63.1 \\
\hline Male & 154 & 36.9 \\
\hline \multicolumn{3}{|l|}{ Level of education } \\
\hline Secondary & 9 & 2.2 \\
\hline Tertiary & 408 & 97.8 \\
\hline \multicolumn{3}{|l|}{ Religion } \\
\hline Christian & 372 & 89.2 \\
\hline Islam & 45 & 10.8 \\
\hline \multicolumn{3}{|l|}{ Marital Status } \\
\hline Currently Married & 193 & 46.3 \\
\hline Single & 221 & 53.0 \\
\hline Widow/Widower & 3 & 0.7 \\
\hline \multicolumn{3}{|l|}{ Type of residence } \\
\hline Urban & 311 & 74.6 \\
\hline Peri-Urban & 61 & 14.6 \\
\hline Rural & 45 & 10.8 \\
\hline \multicolumn{3}{|l|}{ Occupation } \\
\hline Health worker & 75 & 18.0 \\
\hline Civil servant & 82 & 19.7 \\
\hline Private sector & 50 & 12.0 \\
\hline Unemployed & 32 & 7.7 \\
\hline Self-employed & 63 & 15.1 \\
\hline Students & 115 & 27.6 \\
\hline Number of persons in your household Median (IQR) & $5(4,6)$ & Range : 1 - 13 \\
\hline Monthly Income in Naira Median (IQR) & $71000(31500,125000)$ & Range: $10,000-400,000$ \\
\hline
\end{tabular}

\section{Knowledge of Vaccination and COVID-19 Vaccine}

As shown in Table 2, although majority (89.2\%) of the respondents agreed that vaccine is beneficial to health, $23 \%$ reported that they have never received any form of vaccine in their lifetime. Knowledge of COVID -19 vaccine was high (98.8\%) among the respondents. Also, $67.9 \%$ of them reported that their work exposed them to COVID-19 infection. More than one-third (37\%) have tested for COVID-19 (figure 1), and 3.4\% tested positive. On vaccination, three-quarters (75.1\%) reported that they had no access to COVID-19 vaccine, and $74.3 \%$ were not willing to take the vaccine. Reasons given for not willing to take the vaccine (figure 3) were: COVID-19 is a propaganda (7.5\%); fear of adverse effect (21.7\%); pregnancy (4.7\%); safety of vaccine (43.4\%); because I don't have COVID-19 (0.9\%); Parents warning not to take the vaccine (1.9\%); I have no interest (19.8\%). Most (54.9\%) of the respondents preferred the intravenous mode of vaccine administration, and a quarter (25.2\%) preferred any of the modes of administration. As shown in figure 2 , among those who have taken the vaccine $(41.2 \%), 38.2 \%$ said it was mandated by their employer.

Table 2: COVID-19 Vaccine 


\begin{tabular}{|c|c|c|}
\hline Variables & Frequency $(n=417)$ & Percentage (\%) \\
\hline \multicolumn{3}{|l|}{ Is taking of vaccine beneficial to your health? } \\
\hline Yes & 372 & 89.2 \\
\hline No & 45 & 10.8 \\
\hline \multicolumn{3}{|l|}{ Have you ever received any vaccine? } \\
\hline Yes & 321 & 77.0 \\
\hline No & 96 & 23.0 \\
\hline \multicolumn{3}{|l|}{ Does your work expose you to COVID-19 infection? } \\
\hline Yes & 283 & 67.9 \\
\hline No & 134 & 32.1 \\
\hline \multicolumn{3}{|c|}{ Was the result of your COVID19 test positive? $(n=154)$} \\
\hline No & 140 & 33.6 \\
\hline Yes & 14 & 3.4 \\
\hline \multicolumn{3}{|l|}{ Do you have access to take the COVID-19 vaccine } \\
\hline Yes & 313 & 75.1 \\
\hline No & 104 & 24.9 \\
\hline \multicolumn{3}{|l|}{ Are you willing to take COVID19 vaccine } \\
\hline Yes & 310 & 74.3 \\
\hline No & 107 & 25.7 \\
\hline \multicolumn{3}{|l|}{ Which method of the vaccination do you prefer } \\
\hline Any & 105 & 25.2 \\
\hline Injection & 229 & 54.9 \\
\hline Oral & 83 & 19.9 \\
\hline \multicolumn{3}{|c|}{ If you have taken the vaccine, was the vaccine mandated by your employer $(n=170)$} \\
\hline Yes & 65 & 38.2 \\
\hline No & 105 & 61.8 \\
\hline
\end{tabular}

Features of COVID-19 vaccine received by the respondents

Figure 4 presents information on the type of COVID-19 vaccine received by respondents. Among 172 respondents that have received the vaccine, 114 ( $66.3 \%$ ) received Oxford-AstraZeneca, $27(15.7 \%)$ received Moderna, while $17(9.9 \%)$ do not know the name of the vaccine they received.

As regards the dosage, figure 5 showed that more than one-third (39.0\%) have received only first dose while majority (61.0\%) have completed the dosage. Similarly in figure 7, those who didn't receive the vaccine reported some reasons for not doing so, the result was presented in figure 7. About 32(13.1\%) said they don't know where to take the vaccine, $23(9.4 \%)$ said the venue was too distant to their area, $162(66.1 \%)$ doubted the effectiveness of the vaccine, $33(13.5 \%)$ said they are just testing the vaccine on us, and $86(35.1 \%)$ said that the reported side-effect by those who have taken the vaccine was scaring them.

The reported side effects were shown in figure 6. These includes: pain, headache and fever (25\%); arm soreness (2.3\%); itching (2.3\%); sudden stomach ulcer (0.6\%); and $64.5 \%$ reported no side effect.

Unmet need for COVID-19 vaccine

The result in table 3 showed that $74.3 \%$ were willing to take the vaccine in this population, but only $41.2 \%$ were able to take the vaccine. This revealed $33.1 \%$ unmet need for COVID 19 vaccine.

Table 3: Willingness to take COVID-19 vaccine and unmet need

\begin{tabular}{|l|l|l|}
\hline Variables & Frequency (n) & Percentage (\%) \\
Yre you willing to take COVID19 vaccine & & \\
No & 310 & 74.3 \\
Have you been able to take the vaccine & 107 & 25.7 \\
Yes & 172 & 41.2 \\
No & 245 & 58.8 \\
Unmet need for COVID-19 Vaccine & & \\
Unmet need & 138 & 33.1 \\
No Unmet need & 279 & 66.9 \\
\hline
\end{tabular}


Scholars have revealed that $60 \%$ to $72 \%$ herds' immunity is required to cut the chain of COVID- 19 transmission with an assumption of $100 \%$ vaccine efficacy (Kadkhoda, 2021). But in the case of Nigeria where AstraZeneca/Oxford COVID-19 vaccine that was reported to have 63.09\% efficacy (W.H.0, 2021) is the most administered. By estimation, at least $95 \%$ herd immunity is required to cut the chain of COVID-19 transmission in Nigeria.

Reproduction number $\left(\mathrm{R}_{0}\right)$ is 2.5 to 3.5

$$
\text { Herd immunity }=\frac{1-\frac{1}{R_{0}}}{V}=\frac{1-\frac{1}{2.42}}{63.09} 0.95=93.1 \%
$$

Where $\mathrm{R}_{0}$ is the reproduction number (2.42) with intervals ranging between 2.37 to 2.47 according to the estimate reported in a study carried out in Nigeria (Adekunle et al., 2020).

$V$ is the Vaccine efficacy: $V$ for AstraZeneca/Oxford COVID-19 vaccine $=63.09 \%$.

The herd immunity is estimated as $93.1 \%$ if Nigeria continued with the AstraZeneca/Oxford vaccine.

\section{Gap from herd immunity}

This study revealed COVID-19 vaccine uptake rate of $41.2 \%$. Since this study was conducted online, meaning that the $41.2 \%$ rate represented the proportion of those who took COVID-19 vaccine and had access to the internet. A previous study revealed that only $48.0 \%$ of Nigerians have access to the internet (Ceci, 2021). By estimate $41.2 \%$ of the $48.0 \%$ Nigerian who had internet access took the COVID-19 vaccine, this implies that about $19.8 \%$ of Nigerian adults took the vaccine.

\section{Factors associated with COVID-19 vaccine uptake}

After adjusting for confounder, the factors associated with the likelihood of COVID-19 vaccine uptake were presented in table 4. Occupation was associated with COVID-19 uptake. For instance, respondents working in private sector ( $\mathrm{AOR}=0.32,95 \% \mathrm{Cl}=0.11-0.90)$, unemployed $(\mathrm{AOR}=0.29,95 \% \mathrm{Cl}=0.05-1.78)$, selfemployed $(A O R=0.48,95 \% \mathrm{Cl}=0.16-1.46)$, and students $(A O R=0.43,95 \% \mathrm{Cl}=0.15-1.24)$ were less likely to receive COVID-19 vaccine compared to health workers. Those who said COVID-19 vaccine is not beneficial to health $(A O R=0.04,95 \% \mathrm{Cl}=0.01-0.29)$ were less likely to receive the vaccine compared to respondents who said COVID-19 vaccine is beneficial to health. Also, COVID-19 testing was associated with the uptake of COVID-19 vaccine, as those who have tested for COVID-19 (AOR=3.93, 95\% Cl=1.98-7.84) have a higher likelihood of receiving COVID-19 vaccine compared to those who have never tested for COVID-19. In the same vein, respondents who had access to COVID-19 (AOR=3.63, 95\% Cl= 8.04-16.41) were more likely to receive the COVID-19 vaccine compared to those who have no access to COVID-19 vaccine.

Table 4: Factors associated with COVID-19 Vaccine uptake 


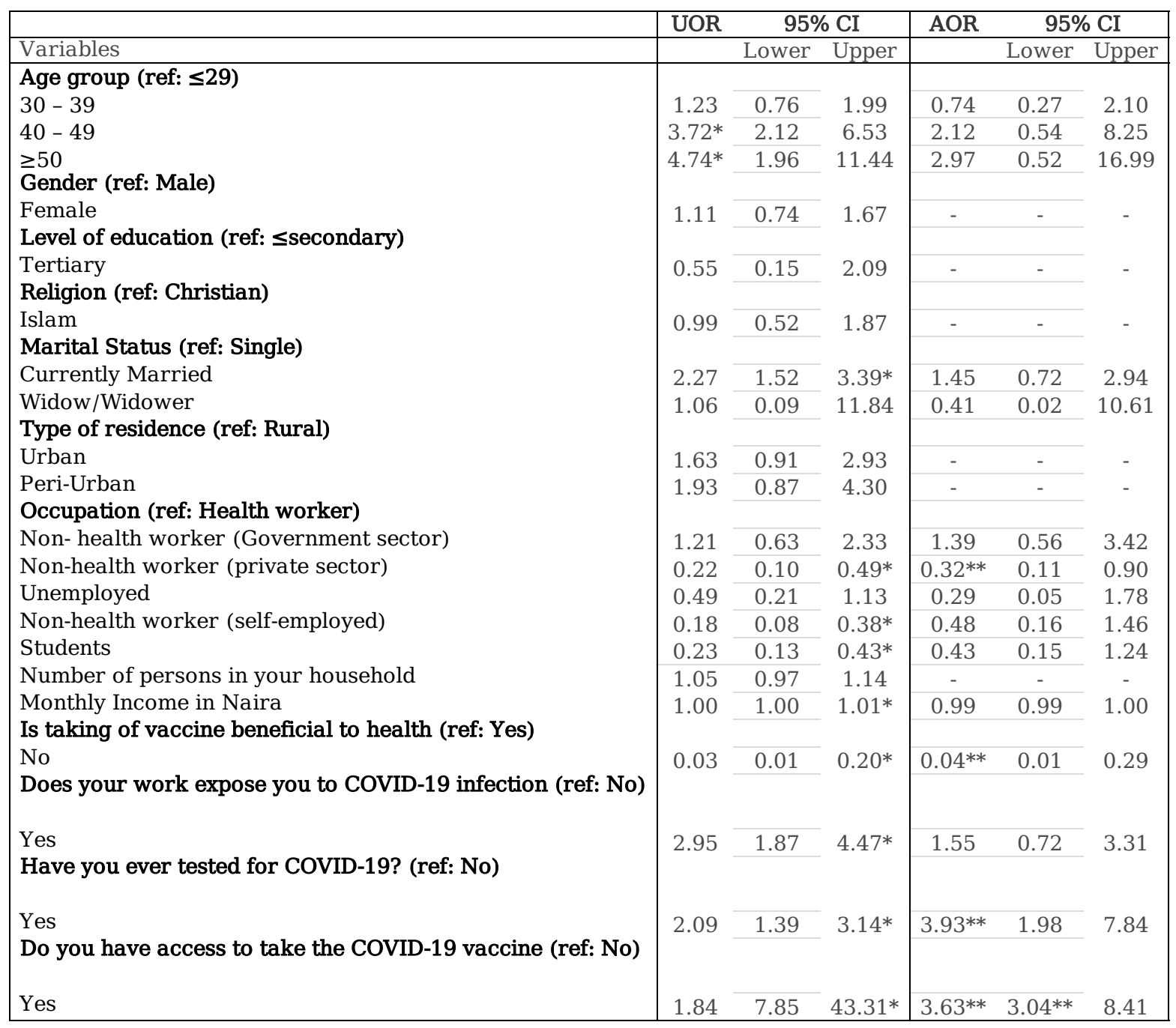

$U O R^{*}$ : unadjusted Odds ratio significant at 5\%; AOR**: adjusted Odds-ratio significant at 5\%;

ref: Reference category

\section{Discussion}

The present survey covered all geo-political zones in Nigeria, with many of the respondents residing in urban areas. In the past few decades, due to migration and urbanization, there has been a surge in the population of urban dwellers. The large number of urban dwellers that participated in this study is not unexpected because it is a web-based study and requires access to a mobile phone, laptop, and internet services which are most readily available in the urban areas. While many respondents in this present study agreed that vaccine is beneficial, one in four persons has never taken any form of vaccine in their lifetime. This is similar to the NDHS report that vaccination coverage in Nigeria is low, one in five children did not receive any of the recommended childhood vaccines (NDHS, 2013; NPC and ICF, 2019). The country is among the list of ten countries in the world where $60 \%$ of all children did not receive the basic vaccine (Piot et al., 2019). This is a pointer to vaccine education and general belief about the COVID-19 vaccine in Nigeria.

\section{COVID-19 vaccine willingness, uptake and unmet need}

A quarter of our respondents expressed unwillingness to uptake the COVID-19 vaccine similar to the 24.3\% reported by Qiao and colleagues (Qiao et al., 2020). Consistent with other studies in Nigeria (Eniade et al., 2021), Ethiopia (Mant et al., 2021), and Jordan (El-Elimat et al., 2021), fear of the safety of the vaccine, fear of adverse effects, the efficacy of vaccine, lack of trust in the government and knowledge about the vaccines were the major reasons for unwillingness to take the COVID-19 vaccine. A previous study among women in Northern Nigeria documented vaccine hesitancy as $13 \%$. Reasons given for the non-uptake of the vaccine include general beliefs and lack of knowledge about the importance of vaccines (Sato \& Takasaki, 2021).

This study revealed COVID-19 vaccine uptake rate of $41.2 \%$, but because this study was conducted online, meaning that the $41.2 \%$ rate represented the proportion of those who took COVID-19 vaccine and had access to the internet. A study have revealed that only $48.0 \%$ of Nigerian have access to the internet (Ceci, 2021). By estimate $41.2 \%$ of the $48.0 \%$ Nigerian who had access to the internet took COVID-19 vaccine, this implied that about $19.8 \%$ of Nigeria have received the vaccine. We also identified that one in every three respondents in this study was willing to take the COVID-19 vaccine but have not (unmet need), because of lack of knowledge about where to access COVID-19 vaccine, belief that the vaccine was being tested on Nigerians, and reported side effects by those who have taken the vaccine. This finding showed that knowledge about access to vaccines and misconceptions were major hindrances to vaccine uptake in Nigeria. The lack of effective and educative awareness about the COVID-19 vaccine could be a reason for the poor awareness. The lack of 
awareness about the COVID-19 vaccine and misconception about the vaccine has a link to politicization, a study has revealed that politicization is a major hindrance to COVID-19 vaccine coverage (Boschiero et al., 2021).

Vaccine completion rate was $61 \%$ in this study. Compared to another study that reported a slightly higher completion rate in the United State of America (Kriss et al., 2021). The variation in the completion rate across countries could be tied to people's beliefs about the vaccine as a lot of those who didn't take the vaccine provided reasons for not taking the vaccine. Provided reasons can be regarded as misconceptions about the vaccine. In the same vein, the majority in this study reported no side effects of the COVID-19 vaccine. The reported side effects of the COVID-19 vaccine included headache and fever, arm soreness, and itching, which are some of the signs reported. This finding is in agreement with the WHO publication on the side effects of the vaccine (World Health Organization, 2021). Further, the reported side effect in this study has been earlier reviewed and confirmed protective and effective to combat the transmission of COVID-19 (World Health Organization, 2021).

\section{Herd immunity}

Regarding herd immunity, we incorporated the vaccine efficacy of the most administered vaccine in Nigeria to estimate a country-specific herd immunity. Based on the vaccine efficacy of $63.09 \%$ (AstraZeneca vaccine), we estimated the herd immunity to be $93.1 \%$ with an interval of $91.7 \%$ to $94.4 \%$, this is a great task to achieve in a country where high vaccine hesitancy was found. Compared to other studies that estimated the threshold for COVID-19 herd immunity between $55 \%$ and $82 \%$ (Schaffer Deroo et al., 2020). Vaccine hesitancy impedes vaccine uptake and the achievement of herd immunity (Dudley et al., 2020).

We proceeded to estimate the herd immunity for a highly effective vaccine such as Moderna, Moderna vaccine have been proven to have high ( $94.1 \%$ ) efficacy (Chagla, 2021). Going by the vaccine efficacy of Moderna, the country-specific herd immunity would be $62 \%$, this implies that a highly effective vaccine would help achieve herd immunity and reduce the chances of COVID-19 transmission in Nigeria

Furthermore, the result showed herd immunity in Nigeria is quite higher (93.1\%) compared to other countries (75.2\%). Also, going by the published proportion $(1.71 \%)$ of fully vaccinated in Nigeria (World Health Organization, 2021), Nigeria is still very far from achieving herd immunity against COVID-19 transmission.

\section{Conclusion And Recommendation}

There is a need for continuous awareness of service centers for COVID-19 vaccine in Nigeria. Government needs to persistently assure and encourage the citizens of the safety and efficacy of the vaccines, so that Nigeria can achieve the desired herd immunity to stop the spread of the COVID-19 infection. Also, this study recommends that administering a highly effective vaccine would result in achievable herd immunity and curb the transmission of the COVID-19 virus.

\section{Limitation}

This study was carried out online; therefore, as a result of inaccessibility to the internet among some Nigerians, the generalizability of some of the findings may not be appropriate. However, the limitation does not erode the findings from this study.

\section{Declarations}

\section{Ethics approval and consent to participate}

The ethical approval for this study was gotten from Adeleke University Ethical Review Committee (AUERC/FBMS/IND/02). All participants provided informed consent to participate in the study by clicking the informed consent button after they were fully informed about their freedom to withdraw from the study at any point. Every tenet of the Helsinki Declaration and other ethi-cal requirements were strictly complied with throughout the study. No identifying information was captured from participants, and the study database was accessible to the only Data manager.

\section{Consent for publication}

All authors give consent for publication of this manuscript in your journal

\section{Availability of data and materials}

Data used for this study will be made available on request

\section{Competing Interest}

We declare that there is no competing interest 


\section{Authors' contribution}

$\mathrm{OO}$ and $\mathrm{AO}$ developed the background of the study, ODE designed the data collection database, carried out the analysis and wrote the result, OY developed the method section. ATO, OO, ODE, FA and AA wrote the discussion. ATO processed the ethical approval. OO, AO, ODE, ATO, FA, AA and OY reviewed and revised the manuscript.

\section{Acknowledgements}

The authors will like to acknowledge the Kobo toolbox (https://kobo.humanitarianresponse.info) data collection platform for facilitating the database for the collection of data for this study

\section{Dedication}

We dedicate this paper to Late Mrs Funke Akintunde (one of the authors) who died on $27^{\text {th }}$, January 2022. May her soul rest in perfect peace.

\section{References}

COVID-19 Repository. (2021). Coronavirus COVID-19 (2019-nCoV). Centre for Systems Science and Engineering (CSSE) John Hopkins University. https://www.arcgis.com/apps/dashboards/bda7594740fd40299423467b48e9ecf6

El-Elimat, T., AbuAlSamen, M. M., Almomani, B. A., Al-Sawalha, N. A., \& Alali, F. Q. (2021). Acceptance and attitudes toward COVID-19 vaccines: A crosssectional study from Jordan. PLoS ONE, 16(4), e0250555. https://doi.org/10.1371/journal.pone.0250555

Eniade, O. D., Olarinmoye, A., Otovwe, A., Akintunde, F. E., Okedare, O. O., \& Aniyeloye, A. O. (2021). Willingness to Accept COVID-19 Vaccine and Its Determinants among Nigeria Citizens: A Web-based Cross-sectional Study. Journal of Advances in Medicne and Medical Research, 33(8), 13-22. https://doi.org/10.9734/JAMMR/2021/v33i830881

Lazarus, J. V., Ratzan, S. C., Palayew, A., Gostin, L. O., Larson, H. J., Rabin, K., Kimball, S., \& El-Mohandes, A. (2020). A global survey of potential acceptance of a COVID-19 vaccine. Nature Medicine. https://doi.org/10.1038/s41591-020-1124-9

Mant, M., Aslemand, A., Prine, A., \& Holland, A. J. (2021). University students' perspectives, planned uptake, and hesitancy regarding the COVID-19 vaccine: A multi-methods study. PLOS ONE, 16(8), 1-16. https://doi.org/10.1371/journal.pone.0255447

NDHS. (2013). Nigeria Demographic Health Survey. Ndhs, 187-188.

NPC and ICF. (2019). Nigeria Demographic Health Survey 2018. National Population Commission (NPC) [Nigeria] and ICF.

OECD. (2021). Enhancing public trust in COVID-19 vaccination: The role of governments (Issue May, pp. 1-27). oecd.org/coronavirus

Piot, P., Larson, H. J., O’Brien, K. L., N'kengasong, J., Ng, E., Sow, S., \& Kampmann, B. (2019). Immunization: vital progress, unfinished agenda. Nature, 575(7781), 119-129. https://doi.org/10.1038/s41586-019-1656-7

Qiao, S., Friedman, D. B., Tam, C. C., Zeng, C., \& Li, X. (2020). Vaccine acceptance among college students in South Carolina: Do information sources and trust in information make a difference? medRxiv: The Preprint Server for Health Sciences. https://doi.org/10.1101/2020.12.02.20242982

Ritchie, H., Ortiz-Ospina, E., Beltekian, D., Mathieu, E., Hasell, J., Macdonald, B., Giattino, C., Appel, C., Rodés-Guirao, L., \& Roser, M. (2020). Coronavirus Pandemic (COVID-19). Our World in Data. https://ourworldindata.org/covid-vaccinations

Sanche, S., Lin, Y. T., Xu, C., Romero-Severson, E., Hengartner, N., \& Ke, R. (2020). High Contagiousness and Rapid Spread of Severe Acute Respiratory Syndrome Coronavirus 2. Emerging Infectious Diseases, 26(7), 1470-1477. https://doi.org/10.3201/EID2607.200282

Sato, R., \& Takasaki, Y. (2021). Vaccine Hesitancy and Refusal: Behavioral Evidence from Rural Northern Nigeria. Vaccines, $9(1023)$. https://doi.org/10.3390/vaccines9091023

Schaffer Deroo, S., Pudalov, N. J., \& Fu, L. Y. (2020). Planning for a COVID-19 Vaccination Program. Journal of the American Medical Association, 323(24), 2458-2459. https://doi.org/10.1001/jama.2020.8711

Wang, J., Jing, R., Lai, X., Zhang, H., Lyu, Y., Knoll, M. D., \& Fang, H. (2020). Acceptance of covid-19 vaccination during the covid-19 pandemic in china. Vaccines, 8(3), 1-14. https://doi.org/10.3390/vaccines8030482

WHO. (2021). Coronavirus disease (COVID-19): Vaccines. https://www.who.int/news-room/q-a-detail/coronavirus-disease-(covid-19)-vaccines? adgroupsurvey=\%7Badgroupsurvey\%7D\&gclid=CjwKCAjwx8ilBhBwEiwA2quaqzuHM7erRgCcYYrSQn58_66Wvg6jYxBPbM1RjwN2CAI2wh_rrBY1ixoC8vwQAvD. 
WHO Africa. (2021). Risks and challenges in Africa's COVID-19 vaccine rollout. https://www.afro.who.int/news/risks-and-challenges-africas-covid-19-vaccinerollout

Adekunle, A. I., Adegboye, O. A., Gayawan, E., \& McBryde, E. S. (2020). Is Nigeria really on top of COVID-19? Message from effective reproduction number. Epidemiology and Infection, 148, e166, Article e166. https://doi.org/10.1017/S0950268820001740

Boschiero, M. N., Palamim, C. V. C., \& Marson, F. A. L. (2021). The hindrances to perform the COVID-19 vaccination in Brazil. Human Vaccines \& Immunotherapeutics, 1-16.

Dudley, M. Z., Privor-Dumm, L., Dubé, È., \& MacDonald, N. E. (2020). Words matter: Vaccine hesitancy, vaccine demand, vaccine confidence, herd immunity and mandatory vaccination. Vaccine, 38(4), 709-711.

Kriss, J. L., Reynolds, L. E., Wang, A., Stokley, S., Cole, M. M., Harris, L. Q., . . Fitter, D. L. (2021). COVID-19 vaccine second-dose completion and interval between first and second doses among vaccinated persons-United States, December 14, 2020- February 14, 2021. Morbidity and Mortality Weekly Report, 70(11), 389.

World Health Organization. (2021). COVID-19 Vaccine Second-Dose Completion and Interval Between First and Second Doses Among Vaccinated Persons Retrieved 11, December, 2021 from https://www.who.int/news-room/feature-stories/detail/the-oxford-astrazeneca-covid-19-vaccine-what-you-need-toknow

Adekunle, A. I., Adegboye, O. A., Gayawan, E., \& McBryde, E. S. (2020). Is Nigeria really on top of COVID-19? Message from effective reproduction number. Epidemiology and Infection, 148, e166, Article e166. https://doi.org/10.1017/S0950268820001740

Boschiero, M. N., Palamim, C. V. C., \& Marson, F. A. L. (2021). The hindrances to perform the COVID-19 vaccination in Brazil. Human Vaccines \& Immunotherapeutics, 1-16.

Chagla, Z. (2021). In high-risk adults, the Moderna vaccine had 94\% efficacy against COVID-19 $\geq 14 \mathrm{~d}$ after the 2nd dose. Annals of Internal Medicine, 174(3), JC28.

Dudley, M. Z., Privor-Dumm, L., Dubé, Ė., \& MacDonald, N. E. (2020). Words matter: Vaccine hesitancy, vaccine demand, vaccine confidence, herd immunity and mandatory vaccination. Vaccine, 38(4), 709-711.

Kriss, J. L., Reynolds, L. E., Wang, A., Stokley, S., Cole, M. M., Harris, L. Q., . . Fitter, D. L. (2021). COVID-19 vaccine second-dose completion and interval between first and second doses among vaccinated persons-United States, December 14, 2020 - February 14, 2021. Morbidity and Mortality Weekly Report, 70(11), 389.

World Health Organization. (2021). COVID-19 Vaccine Second-Dose Completion and Interval Between First and Second Doses Among Vaccinated Persons Retrieved 11, December, 2021 from https://www.who.int/news-room/feature-stories/detail/the-oxford-astrazeneca-covid-19-vaccine-what-you-need-toknow

\section{Figures}

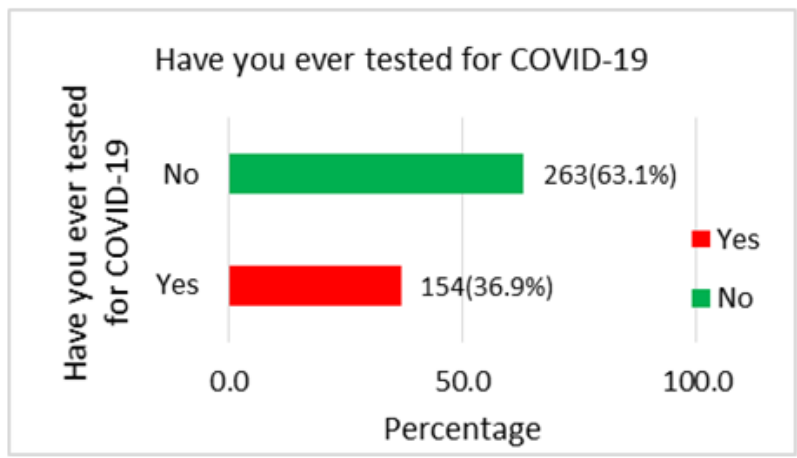

Figure 1

COVID-19 testing 


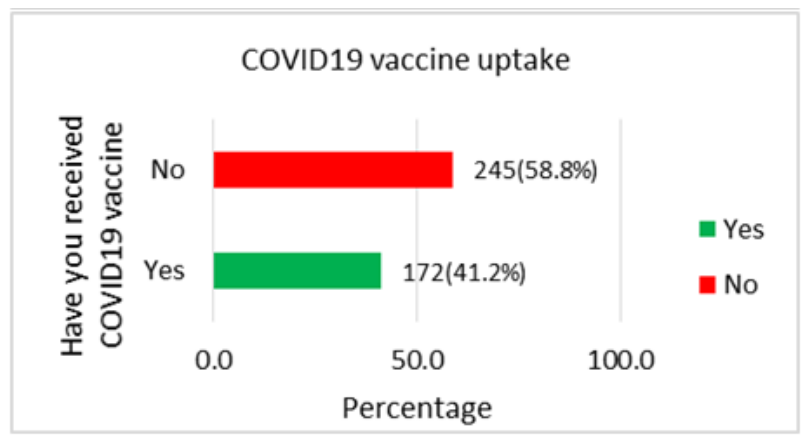

Figure 2

COVID-19 Vaccine uptake

\section{Reason for not willing to take the vaccine}

$$
\begin{array}{ll}
\text { - COVID-19 is a Propaganda } & \text { - Fear of a dverse effect } \\
\text { - Pregnancy } & \text { " Safety of vaccine } \\
\text { - I don't have COVID } & \text { - Par ents warning not to take vaccine } \\
\text { - No interest } &
\end{array}
$$

Figure 3

Reason for not willing to take the vaccine

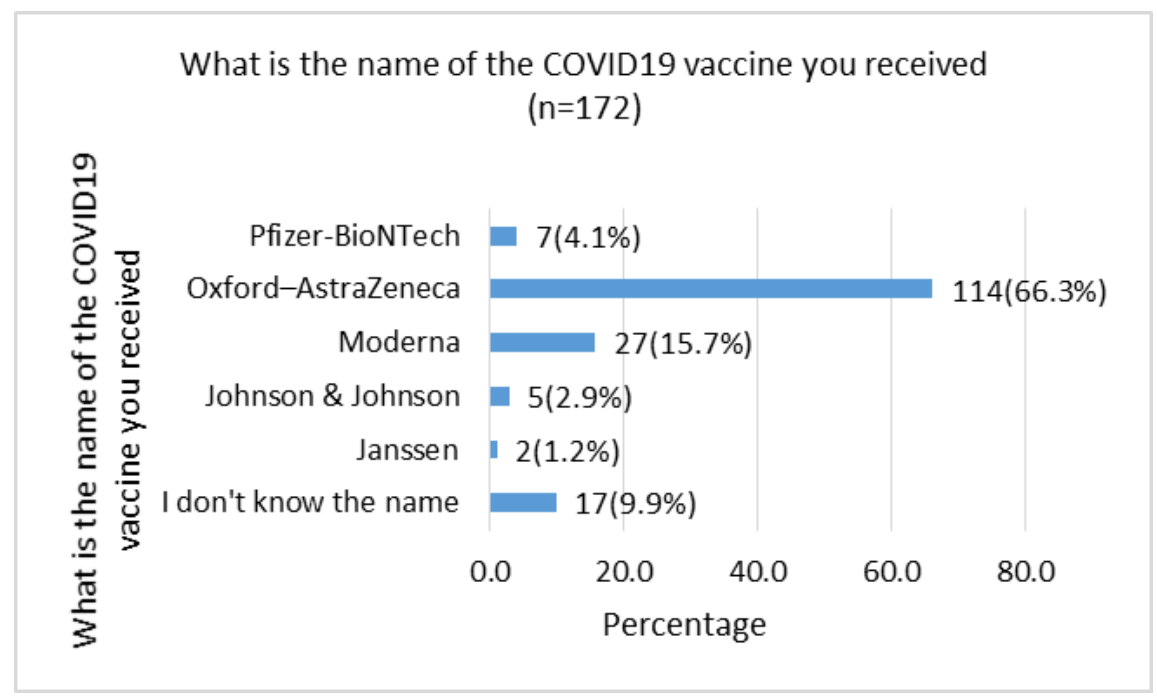

Figure 4

Name of vaccines received 


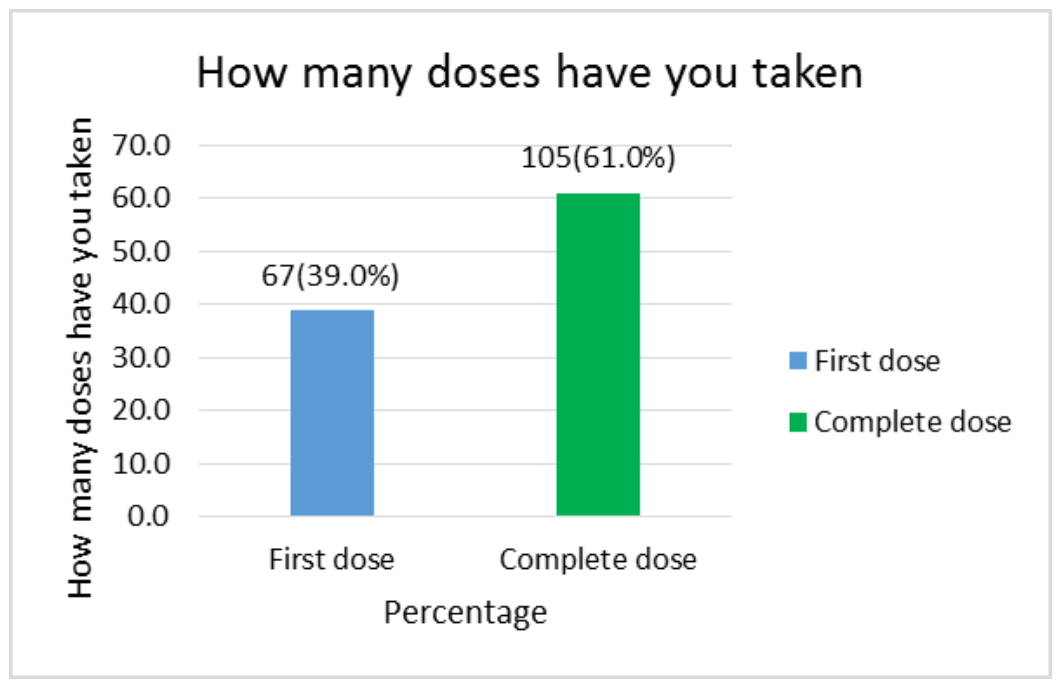

Figure 5

Dosage taken

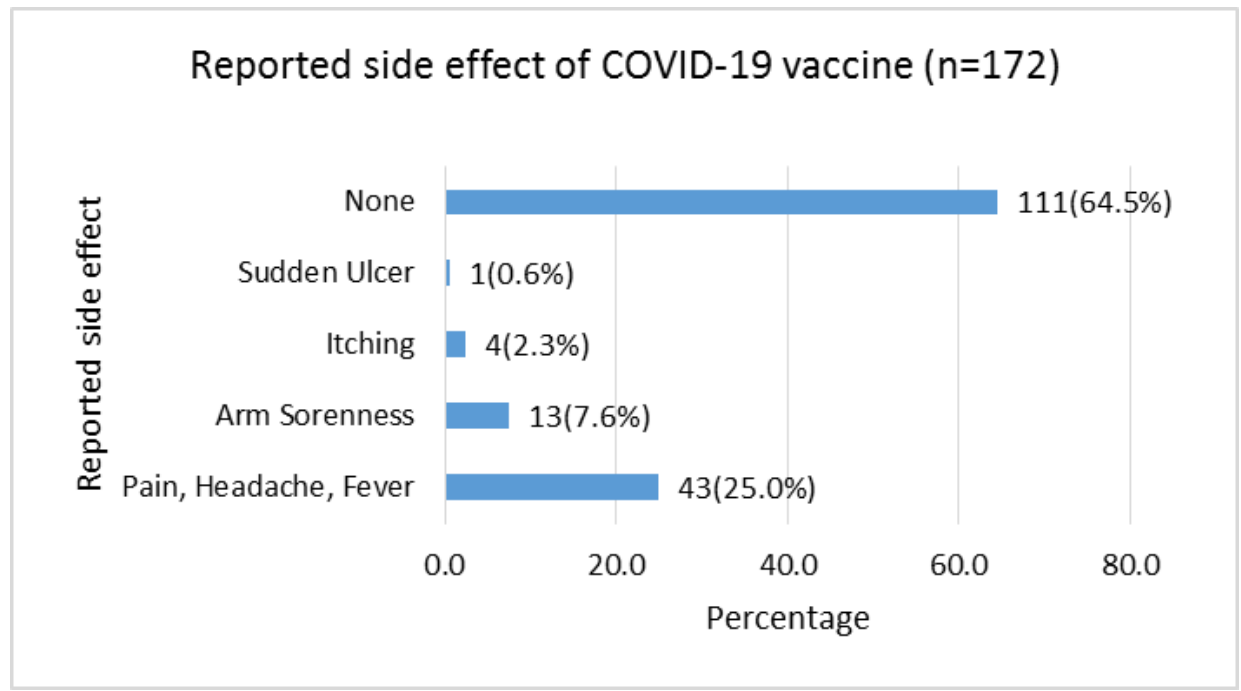

Figure 6

Reported side effect of COVID-19 vaccine

What made you not to receive the vaccine? Multiple choice

$$
(n=245)
$$

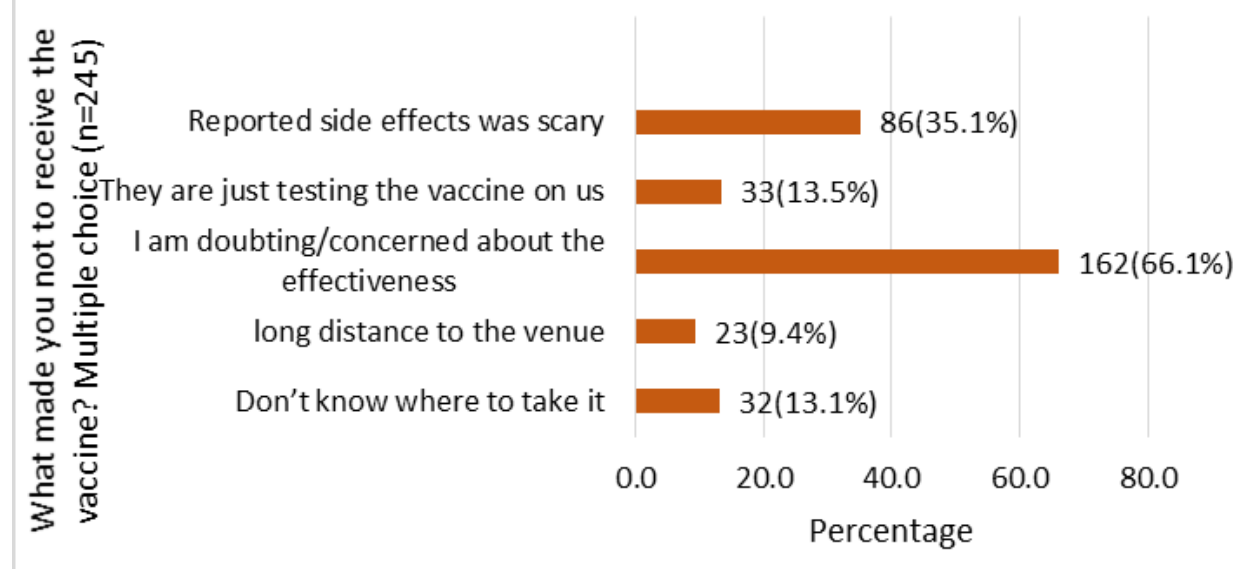

Figure 7 
Reasons for not receiving the vaccine

Page 13/13 